AIAA 2000-1596

\title{
ANALYSIS AND TEST OF REPAIR CONCEPTS FOR A CARBON-ROD REINFORCED LAMINATE
}

\author{
Donald J. Baker* \\ Vehicle Technology Directorate - ARL \\ NASA Langley Research Center \\ Hampton, Virginia 23681 - 2199 \\ and \\ Carl Q. Rousseau** \\ Bell Helicopter Textron \\ Ft. Worth, TX 76101
}

\begin{abstract}
$\underline{\text { Abstract }}$
The use of pultruded carbon-epoxy rods for the reinforcement of composite laminates in some structures results in an efficient structural concept. The results of an analytical and experimental investigation of repair concepts of completely severed carbon-epoxy rods is presented. Three repair concepts are considered: (a) bonded repair with outside moldline and inside moldline doublers; (b) bonded repair with fasteners, and (c) bonded repair with outside moldline doubler only. The stiffness of the repairs was matched with the stiffness of the baseline specimen. The failure strains for the bonded repair with fasteners and the bonded repair with an outside moldline doubler exceeded a target design strain set for the repair concepts.
\end{abstract}

\section{Introduction}

The use of prefabricated pultruded carbon-epoxy rods has reduced the manufacturing complexity and cost of composite structures without compromising structural efficiency. This concept of replacing conventional unidirectional carbon fibers with carbon-epoxy rods embedded in a syntactic adhesive minimizes fiber waviness and increases laminate stiffness and strength. The pioneering research and development work for carbon-rod reinforced composite structures was done by Bell Helicopter Textron, NASA, and the Air Force and is outlined in references 1-10. Before these carbon-epoxy rods can be used in service, the repairability of a laminate

\footnotetext{
* Aerospace Engineer, Mechanics and Durability Branch

** Principal Engineer, Research Structures

Copyright $\odot 2000$ by the American Institute of Aeronautics and Astronautics, Inc. No copyright is asserted in the United States under Title 17, U.S. Code. The U.S. government has a royalty-free license for government purposes. All other rights are reserved by the copyright owner.
}

that is reinforced with these rods must be investigated.

The main objective of this project was to demonstrate that, despite their extremely high strength and stiffness, carbon-rod reinforcement could be effectively repaired, even if fully severed. The approach taken was to design three different repairs, then build and test one specimen of each in order to validate the design approach. A finite element analysis was conducted using 3-D finite elements and the predicted strain results are compared with the experimental strains.

\section{$\underline{\text { Symbols }}$}

$\begin{array}{ll}\text { A } & \text { Area, inches }{ }^{2} . \\ E & \text { Axial Modulus, Msi. } \\ \mathrm{P} & \text { Load,lbs. } \\ \varepsilon_{\mathrm{x}} & \text { Strain, in./in. }\end{array}$

Test Specimens

In designing a repair for a fully severed carbon-rod reinforcement, to be identified as a rodpack in this paper, it was evident that (a) a scarf repair was mandatory, and (b) an aggressive scarf angle and high scarf bondline stress were necessary. Both IML (Inside Mold Line) and OML (Outside Mold Line) doublers were desirable, but it was realized that an IML doubler might not always be possible. Also, no analytical approach was able to demonstrate whether bolting through the bonded scarf and doublers would help or hurt the overall strength of the repair. Thus, the three repair concepts were: (a) bonded repair - uses all bonded or cure-in place components and shall be identified as the bonded specimen in the remainder of the this paper; (b) bolted repair - adds fasteners along the centerline of the bonded repair specimen and shall be identified as the bolted specimen; (c) no-IML repair - bonded repair with a different scarf angle and only an OML doubler (different from (a)) and will be identified as the no-IML specimen for the remainder of the paper.

1

American Institute Of Aeronautics and Astronautics 
The objective in realistic structural repair design is simply to restore design ultimate strength. Due to design requirements such as impact damage tolerance and the limitations of local design details, the operating design ultimate strains are on the order of $3,500 \mu$ in./in. for traditional tape designs and no more than 4,500 $\mu$-in./in. for rodpacks. Adding a $30 \%$ factor for statistical and environmental knockdowns, the target design strain for all three repairs was set at 6,000

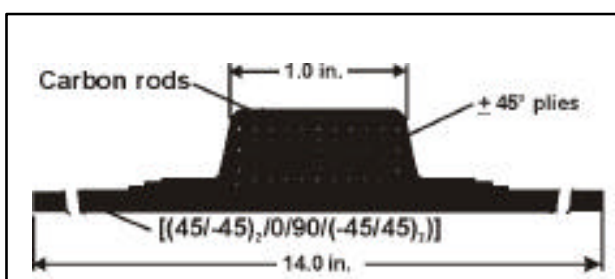

a) Cross-section of baseline specimen

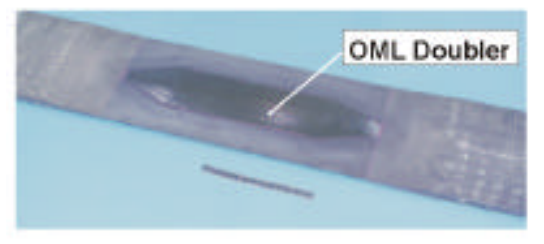

c) Bonded repair

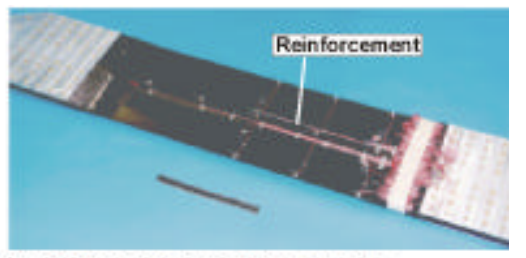

b) Baseline specimen with aluminum end fittings

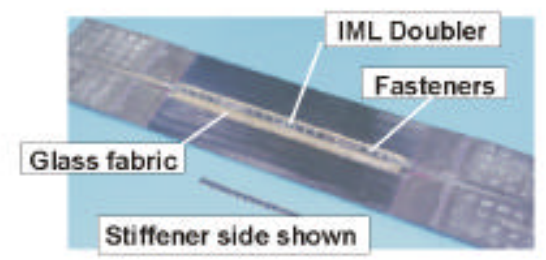

d) Bolted repair

Figure 1. Photographs of the baseline, bolted and bonded specimens

$\mu$-in./in. The scarfed inserts were sized by matching the EA of the removed rodpack and skin. The scarfto-rodpack and doubler-to-specimen bondline stresses were calculated using a strength-ofmaterials method and a rigid-perfectly-plastic assumption of adhesive material response. Limiting the bondline shear stress to 4,000 psi (a much higher allowable than is typically used), the scarf angles, doubler lay-ups, and doubler lengths and tapers were separately chosen for the bonded and the no-IML repairs. The repair length was limited to 36 inches which is a typical spacing of ribs in an aircraft wing. As expected, the no-IML repair yielded a longer scarf, larger OML doubler, and more load path eccentricity. For the bolted repair, the bonded repair configuration was used, and the fastener quantity, diameter, and pitch were selected such that the fasteners could carry all of the load in the scarf bondline.

The basic specimens were fabricated on an aluminum IML tool with an OML caul sheet. The OML side was bagged and the parts were autoclave- cured using the appropriate Bell Helicopter processspecification. The baseline test specimen cross section is shown in figure 1a. The skin is a [(45/-45) $2 / 0 / 90 /(-$ $45 / 45)_{2}$ ] laminate of IM7/8552 carbon-epoxy tape material. The 1.0-inch wide carbon-rod reinforcement (rodpack) is formed from four layers of IM7 carbonepoxy rods (Neptco, 0.067-inch diameter) embedded in a syntactic adhesive (Hysol HC9872) and sandwiched between layers of [ \pm 45$]$ IM7/8552 carbon-epoxy tape which extends over the skin. Each end of the specimen is reinforced with a $[ \pm 45]$ tab for attaching the aluminum load introduction fittings. This specimen will be identified as the baseline specimen for the remainder of this paper. A photograph of the baseline specimen

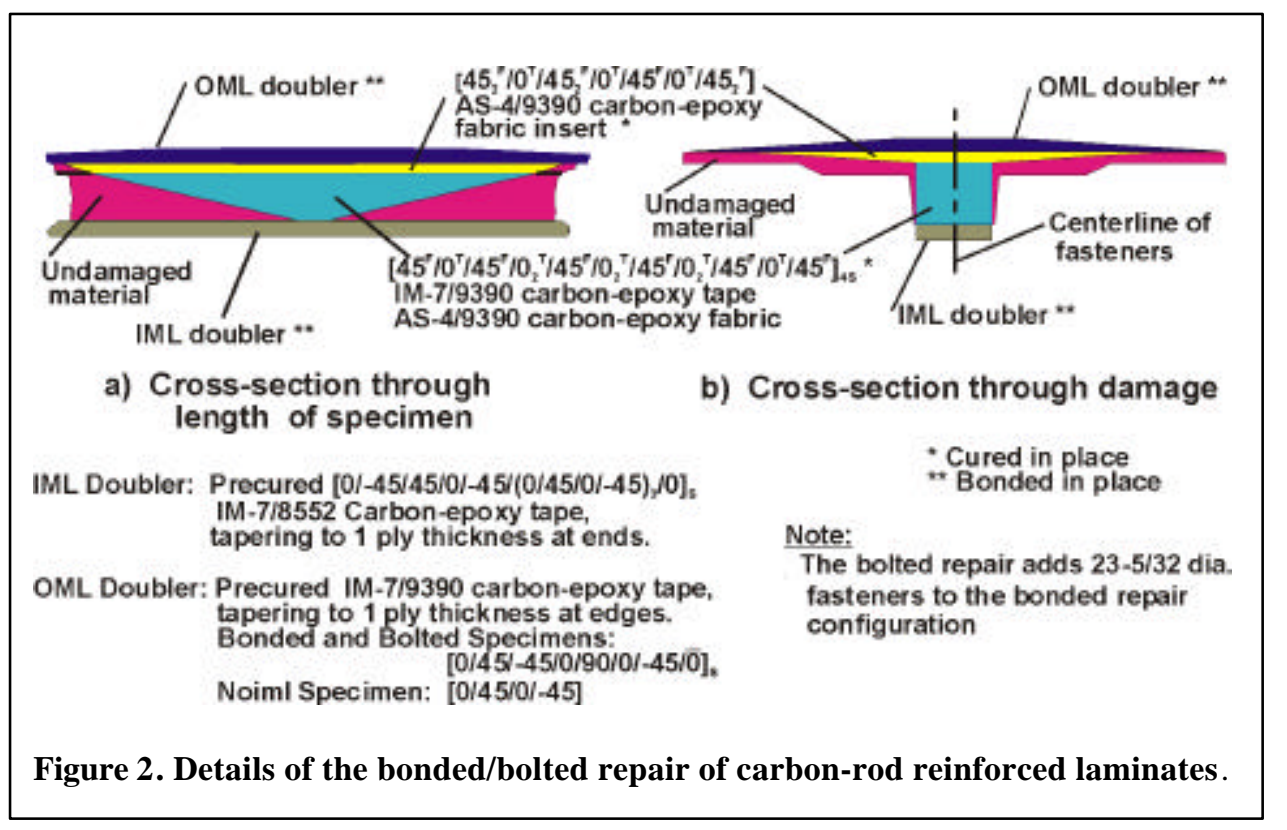

2

American Institute Of Aeronautics and Astronautics 
with the aluminum load introduction fittings is shown in figure $1 \mathrm{~b}$. The test section is 36-inches long and the overall specimen length is 70 inches not including the aluminum end fittings. The aluminum fittings are bolted to the loadiing tabs. The bonded repair and bolted repair specimens are shown in figures $1 \mathrm{c}$ and $1 \mathrm{~d}$, respectively.

The simulated damaged rods and skin are removed by machining through the specimen at the damage location and then machining a taper in each direction away from the damaged area. The simulated damage and scarf was machined out using a numerically controlled end-mill, but close-tolerance repair scarf joints are possible for on-aircraft repair using specialized jigs and grinding tools.

The wet-lay-up scarfed inserts that replace the rodpacks and the skin plugs were fabricated in-situ from dry carbon plain- and uni-weave fabric with EA9390 resin. Details of the repair inserts are shown in figure 2 .

The inserts are cured using a double-vacuum-bag debulk/heat-blanket cure process developed by Bell Helicopter and the U. S. Navy for tiltrotor structural repairs. This repair process yields virtually voidfree, high volume fraction laminates with mechanical properties approaching that of prepreg. Note that the hole due to full rodpack severance must be closed in order to perform the wet lay-up. One ply of glass fabric precured onto the IML (see figure 1d) was used for these specimens (alternative tooling aids would be required for an on-aircraft repair). The $\left[0 / \mu 45 / 0 /-45 /(0 / 45 / 0 /-45)_{3} / 0\right]_{\mathrm{s}}$ IM7/8552 carbon-epoxy tape IML doublers and the $[0 / 45 /-45 / 0 / 90 /-45 / \overline{0}]_{\mathrm{s}}$ or the [0/45/0/-45] IM7/8552 carbon-epoxy tape OML doublers were fabricated from prepreg tape and fully autoclave cured prior to installation on the specimens. These IML and OML doublers were bonded in place with heat-blanketcured EA9340 paste and AF163 film adhesives, respectively, simulating realistic one-sided-access repair schemes.

\section{Test Procedure}

All specimens were instrumented with strain gages. The gage layout for the baseline specimen and the bonded repair specimen are shown in figure 3 . The baseline specimen has 38 strain gages and the repaired specimens had 24 or 25 strain gages. The specimen elongation was measured with a linear variable displacement transducer (LVDT) measuring the change in distance between the loading pins.

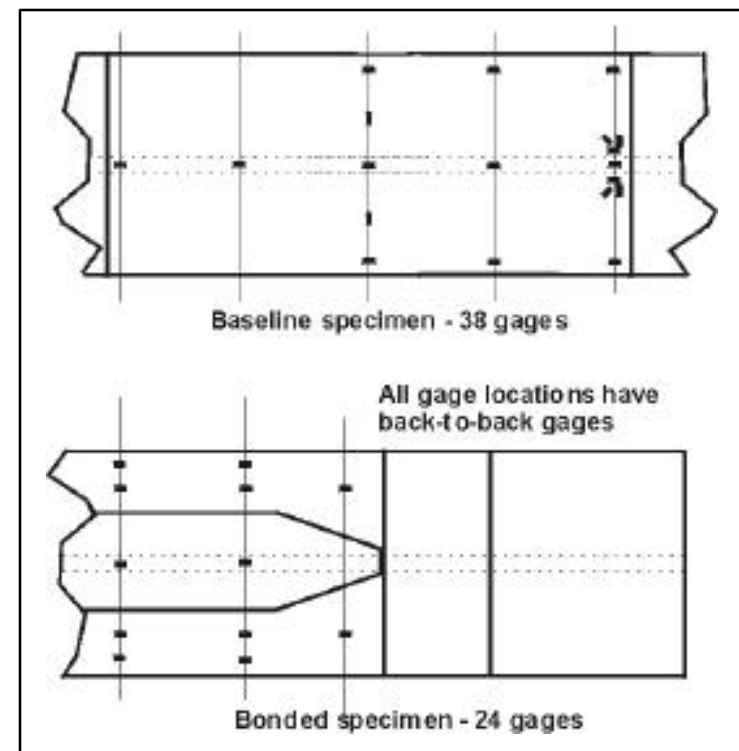

Figure 3. Strain gage locations.

All specimen tests were performed at room temperature and in the as-fabricated condition. The specimens were placed between the clevises of a hydraulic test machine and loaded in tension at a rate of approximately 10,000 $\mathrm{lbs} . / \mathrm{min}$. A video camera was used to monitor the specimen during the tests. The load, strain, and specimen elongation were recorded with a computer controlled data acquisition system for each test.

\section{$\underline{\text { Analysis }}$}

A linear analysis of the specimen response was performed using MSC/NASTRAN (ref 11), Version 70.5, and 8-node brick or tetrahedron elements. Since the specimen is symmetric in two planes only one-fourth of the specimen was modeled. The finite element models of the baseline specimen and the bonded specimen are shown in figure 4 . The models for the repaired specimens do not include the adhesive used in attaching the doublers. A perfect bond is assumed between the cured in-place inserts and the basic material. All the models include the composite load introduction tabs and the aluminum load introduction fittings. The aluminum fittings are attached to the loading tabs with rigid links. The predicted displacement results for the baseline specimen; the bonded specimen; and the noIML specimen corresponding to an applied load of 100 kips are shown in figure 5a. The effect of the carbonrods in shifting the specimen neutral axis is demonstrated in the figure with the out-of-plane bending. All specimens deflect in the $+\mathrm{z}$ direction. The baseline specimen has the largest out-of-plane displacement with the no-IML specimen the next largest. The bolted specimen has very little out-of-plane deflection at the reinforcement but the skin deflects in the $-\mathrm{z}$ direction. 
The predicted $\mathrm{x}$-direction strain $\left(\varepsilon_{\mathrm{x}}\right)$ for the baseline specimen, the bolted specimen, and the noIML specimen are shown in figure 5b. The maximum $\varepsilon_{\mathrm{x}}$ strain for the baseline specimen is at the edge of the skin adjacent to the reinforcing tab, very likely the result of the stiffness mismatch between the laminate and the load introduction tab. The maximum strain in the repaired specimens is in the basic specimen at the termination of the repaired area.

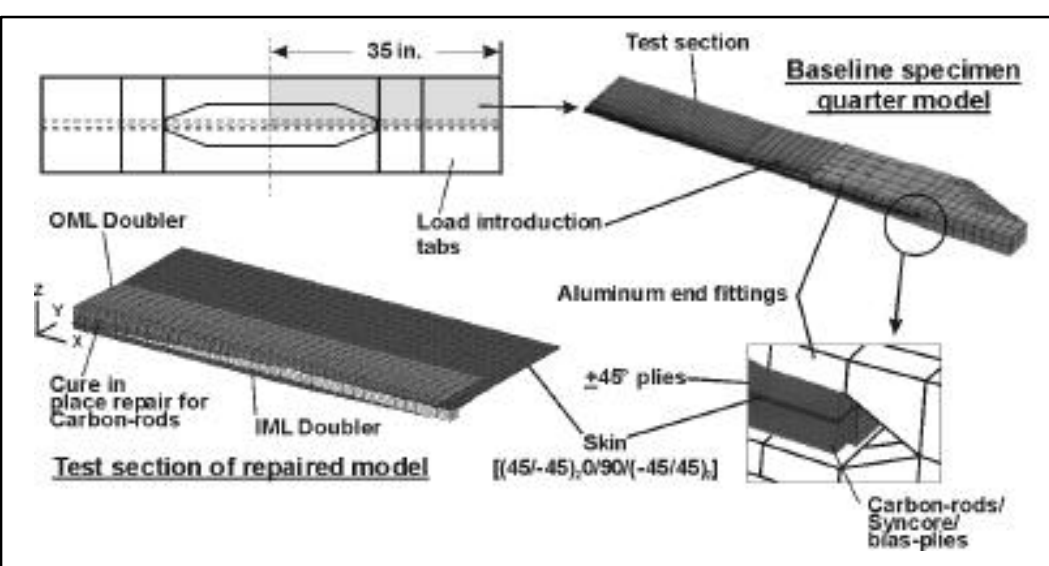

Figure 4. Finite element models of the baseline and repaired specimens.

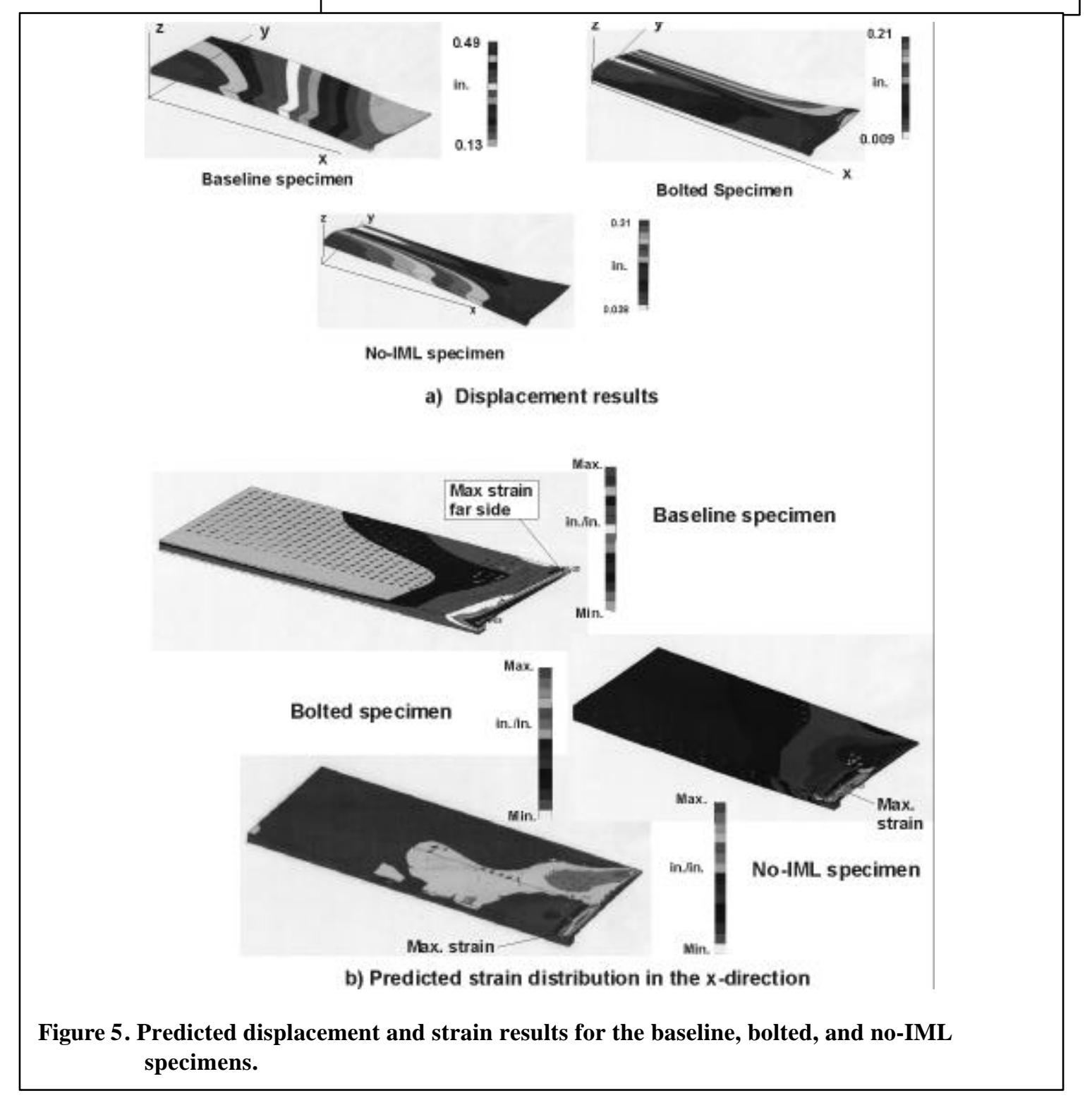




\section{Results and Discussion}

The baseline specimen and the three types of repaired specimens have been tested to failure in tension and the resulting failure loads are shown in column 3 of Table 1. The load at first audible noise from the specimen is given in column 2. The computed mid-section EA properties are shown in column 4 . The computed strains (P/EA) at the midsection are shown for each specimen column 5 . Column 6 lists the far field strains at failure for each specimen. Each specimen type will be discussed in the following paragraphs followed by a comparison between the specimens. shown in figure 6a. The specimen mid-length strain on the centerline of the stiffener appears linear to failure while the strain at one of the edges (box symbol) of the specimen drops at the load drop but the opposite edge strain (triangle symbol) increases at the load change. The results from strain gages located near the reinforced end are shown in figure $6 \mathrm{~b}$. The effect of the rod reinforcement on the section bending can be seen in the difference in the strain of the back-to-back gages (filled and open circles) on the centerline reinforcement. This type of response can be expected when looking at the predicted deflected shape in figure $5 \mathrm{a}$. The strain in the reinforcement also increases when the load drops. The strain gages on the skin do not indicate any large

Table 1. - Failure loads and strain for carbon-rod reinforced specimens.

\begin{tabular}{cccccc}
\hline \hline Specimen & $\begin{array}{c}\text { Load at first } \\
\text { audible noise, } \\
\text { kips. }\end{array}$ & $\begin{array}{c}\text { Failure load, } \\
\text { kips. }\end{array}$ & $\begin{array}{c}\text { EA, } \\
\text { Msi-in }{ }^{2} .\end{array}$ & $\begin{array}{c}\text { Strain (P/EA) at } \\
\text { specimen mid- } \\
\text { length, } \mu \text {-in./in. }\end{array}$ & $\begin{array}{c}\text { Far field strain } \\
\text { (P/EA) } \\
\mu \text {-in./in }\end{array}$ \\
\hline Baseline & 136 & 142.9 & 10.76 & 13,280 & 13,280 \\
Bonded & 44 & 85.6 & 17.06 & 5,017 & 7,955 \\
Bolted & 46 & 108.2 & 17.06 & 6,342 & 10,056 \\
No-IML & 77 & 78.5 & 12.48 & 6,290 & 7,296 \\
\hline \hline
\end{tabular}

Baseline Specimen The baseline specimen failed at 142.9 kips of applied load (Table 1) with a computed strain at failure of 13,280 $\mu$-in./in. This failure strain in the baseline specimen is more than three times a typical operating design ultimate strain for the tape material and more than two times the target design strain for the repaired specimens. The first audible noise was at approximately 136 kips. of applied load. A load drop from 137.7 kips to 135.3 kips is shown in the load-strain results (figure 6) before increasing again to failure. This load drop is consistent with the audible noise. The results for the strain gages at the mid-length of the specimen are bending. The strain in the gage with the open box symbol (figure 6b) increases off scale when the load drops which is a good indication that the failure initiated in the area of the gage. To support this a photograph of the failed baseline specimen is shown in figure 7 , which

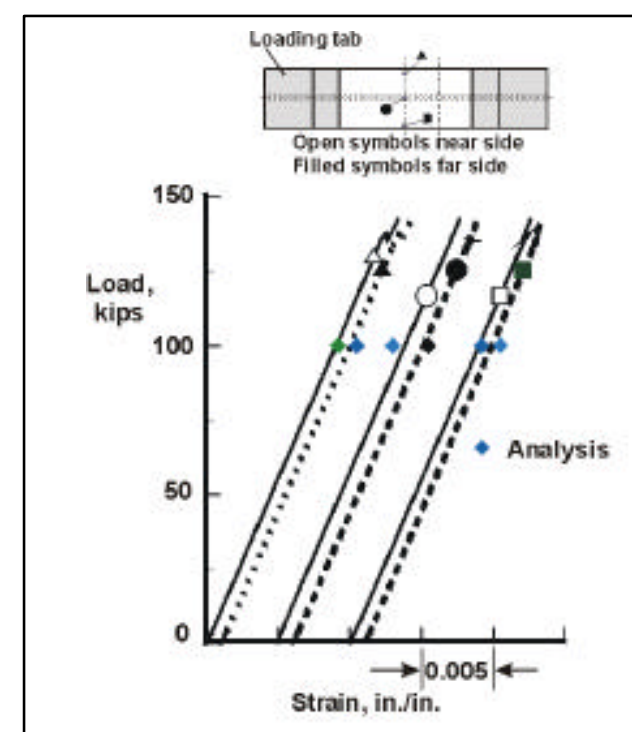

a) Strain results at specimen mid-length

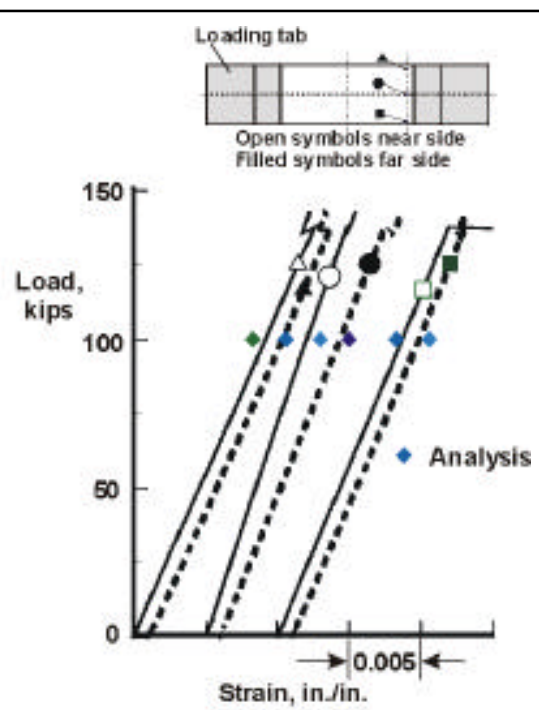

b) Strain results at specimen end adjacent to loading tab

Figure 6. Load as a function of strain results for the baseline specimen. 


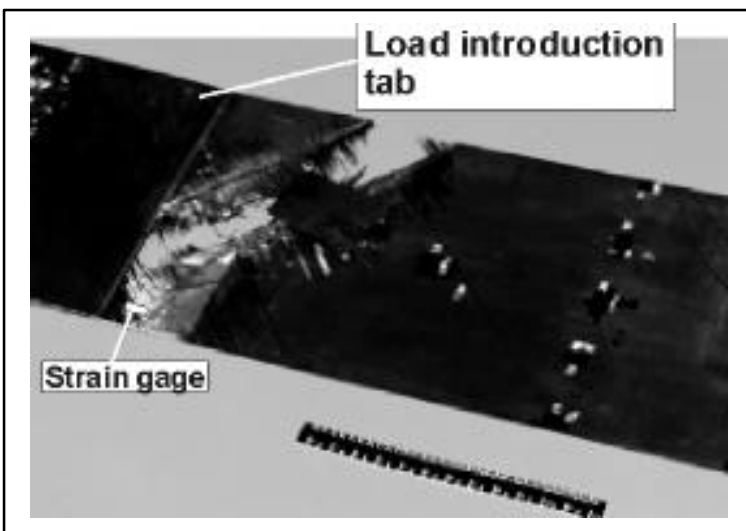

Figure 7. Failed baseline specimen.

indicates that the specimen failed at the location of the gage. The elongation of the baseline specimen measured between the loading pins is shown in figure 8. The slope of the experimental curve between 50 kips and 125 kips is 193.5 kips/in. Also shown in the figure is the computed elongation, which has a slope of the $267.4 \mathrm{kips} / \mathrm{in}$. There are many variables that can contribute to the difference between the experimental and computed elongation, such as loading pin bending, attach fastener bending, hole elongation, etc. The stiffness of the baseline specimen is 72 percent of the computed stiffness. The lag in the response up to 50 kips shown in figure 8 is a result of the slack in the test machine.

The computed strains are shown in figure 6 as diamond symbols. The computed strains are within $11 \%$ of the experimental strains and compare well with the experimental strains.

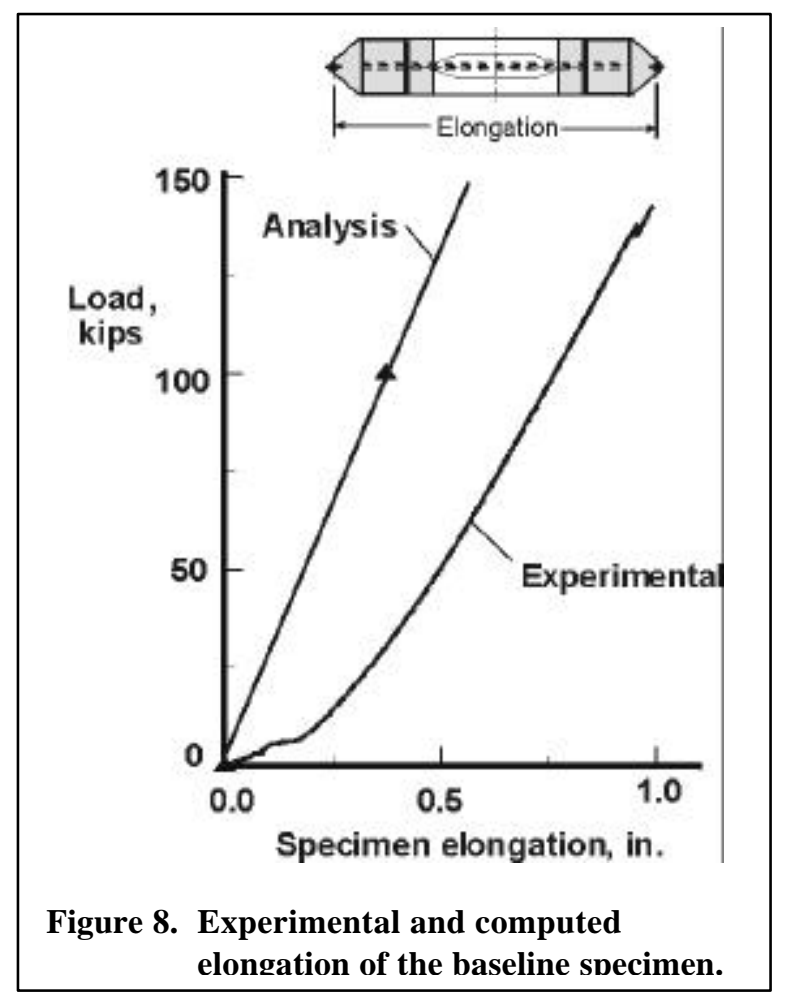

gages along the centerline of the specimen. At 57 kips the OML doubler delaminated between the first and second ply as shown by the dropping of strain to zero at the open circle locations in figure 9a and to a very small strain at the quarter point as shown by the open circle locations in figure $9 \mathrm{~b}$. At 70 kips a similar failure occurred on the IML doubler where the strain (filled circle in fig.6a) went to zero at the mid-length of the specimen and the strain in the IML doubler at the quarter point went off scale. The specimen continued to carry
Bonded Specimen The bonded specimen failed at 85.6 kips (Table 1) and at a computed strain of $5,017 \mu$-in./in. at failure. This failure strain is 84 percent of the target design strain for the repaired specimens. The first audible noise was at approximately 44 kips and continued at random intervals until failure. The strength retention of the bonded specimen is 60 percent of the baseline specimen. The load as a function of strain results are shown in figure 9. The first noticeable change in the response occurred at a load of approximately 50 kips in the

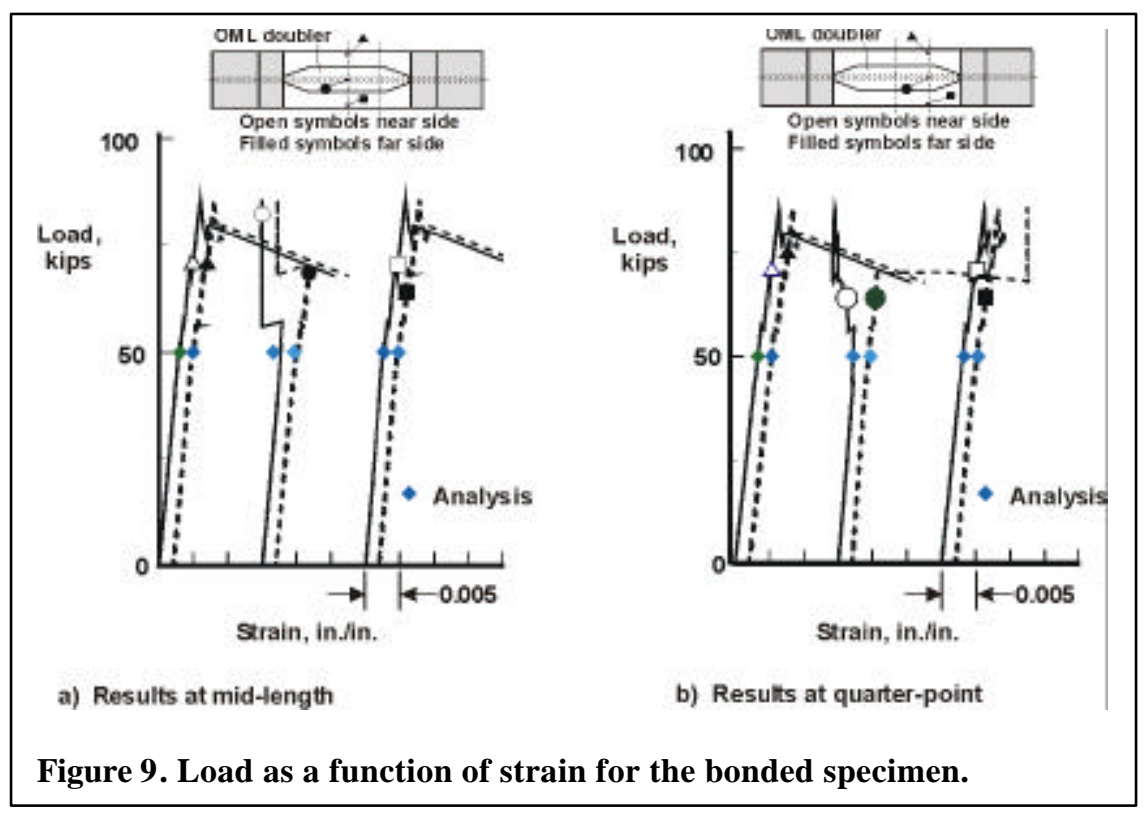




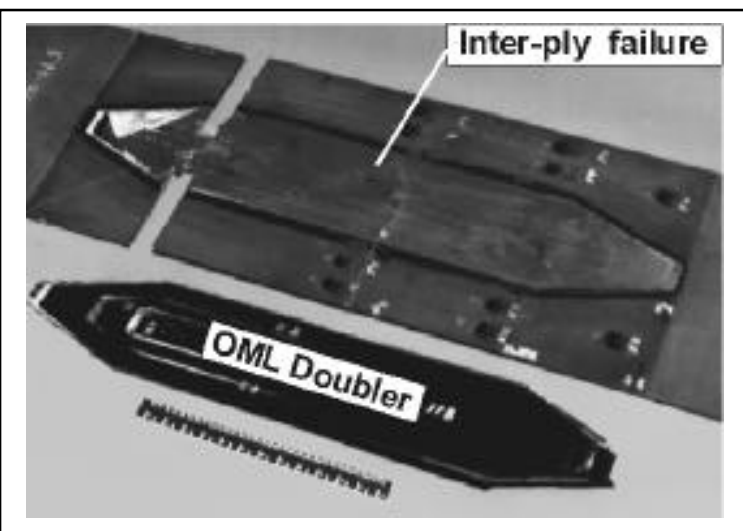

Figure 10. Failed bonded specimen.

load until final failure as can be seen in the other strain gages shown in figure 9. The specimen failed across the end of the machined taper in the rodpack as shown in figure 10. Analysis shows that the strain in the rodpack near the end of the machined tapered cut used in the repair doubles when the doublers are removed. The elongation of the bonded specimen measured between the loading pins is shown in figure 11. Also shown in the figure is the computed elongation. It is impossible to determine a stiffness for the bonded specimen since the failure started near 50 kips and the machine lag effects the results below 50 kips. The progressive delamination of the doublers can also be observed in figure 11 by the load drops as the specimen was loaded to failure.

The computed strains for a load of 50 kips are shown in figure 9 as the diamond symbols. Good agreement is shown between the computed and experimental strains except for the strain in the OML doubler at the specimen mid-length.

Bolted Specimen The bolted specimen failed at 108.2 kips (Table 1) and at a computed strain of $6,342 \mu$-in./in. at failure. This failure strain is 106 percent of the target design strain for the repaired specimens. The first audible noise was at approximately 46 kips and continued at random intervals until failure. The strain increases monotonically at the mid-length of the specimen until the load reaches the failure load. The strain in the OML doubler (open circle)

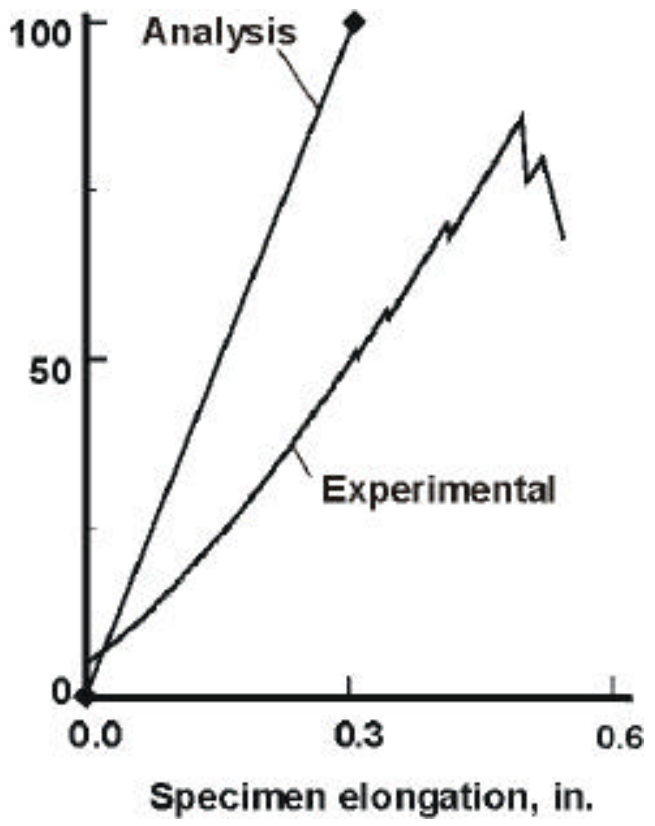

Figure 11. Experimental and computed elongation of the bonded specimen.

at the quarter-point location starts to drop at approximately $70 \mathrm{kip}$ load and continues to drop until failure. Strain in the IML doubler also starts to drop at approximately 70 kips but at a lower rate than in the OML doubler. Failure started in the specimen with the bolts pulling through the tapered end of the OML doubler as the IML doubler was failing in the tapered end. The strength retention of the bolted specimen is 76 percent of the baseline specimen. Final failure was at the end of the machined taper for the repair as can be seen in figure 13. The elongation of the bolted specimen 


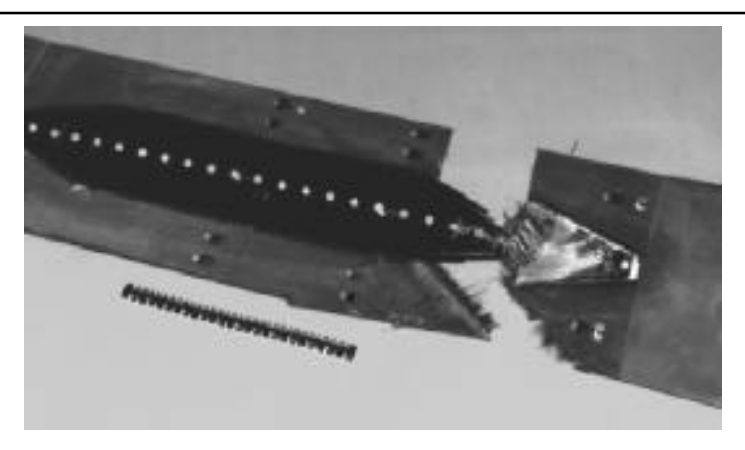

Figure 13. Failed bolted specimen.

measured between the loading pins is shown in figure 14. The slope of the experimental curve between 50 kips and 100 kips is 199.7 kips/in. Also shown in the figure is the computed elongation, which has a slope of the 325.8 kips/in. The stiffness of the bolted specimen is 61 percent of the computed stiffness. The start of the doubler failures at 70 kips did not appear to effect the overall specimen stiffness.

The computed strains are shown in figure 12 as the diamond symbols. Good agreements are shown between the computed and experimental strains in the skin (triangles and squares) and are within 10 percent of the experimental strains. The computed strain in the OML doubler at the specimen midlength is less than the experimental strain while there is a good agreement at the quarter-point. The analysis over predicts the strain in the IML doubler at both locations.

\section{No-IML Specimen \\ The no-IML} specimen failed at 78.5 kips and a computed strain of 6,290 $\mu$-in./in. at failure. This failure strain is 104 percent of the target design strain for the repaired specimens. The strength retention of the no-IML specimen is 55 percent of the baseline. The load as a function of strain results are shown in

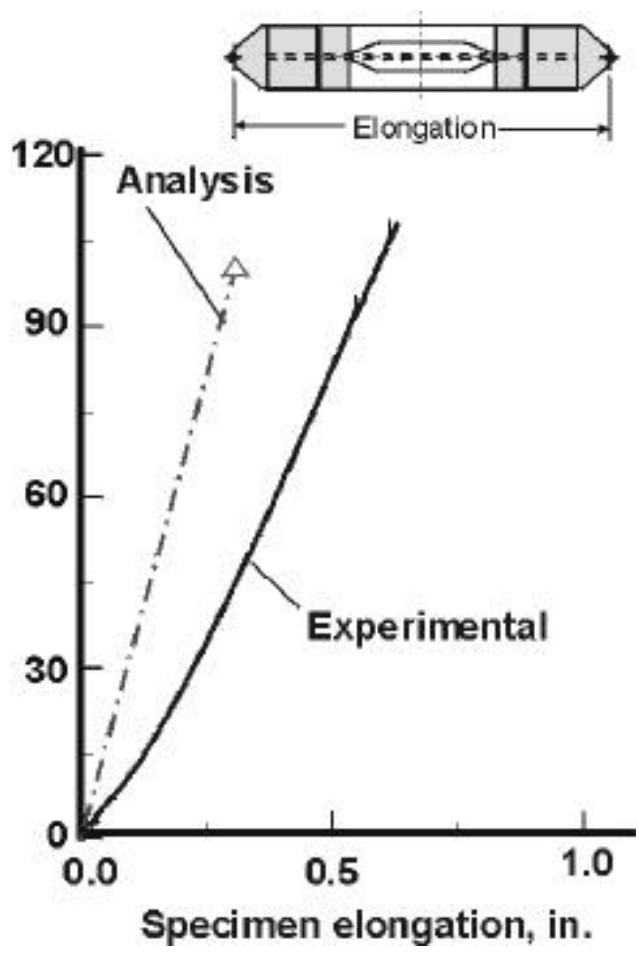

Figure 14. Experimental and computed elongation for the bolted specimen.

figure 15. The strain in all gages increases monotonically until the load is near failure. The specimen failed at mid-length as shown in figure 16 . The elongation of the no-IML specimen measured between the loading pins is shown in figure 17 . The

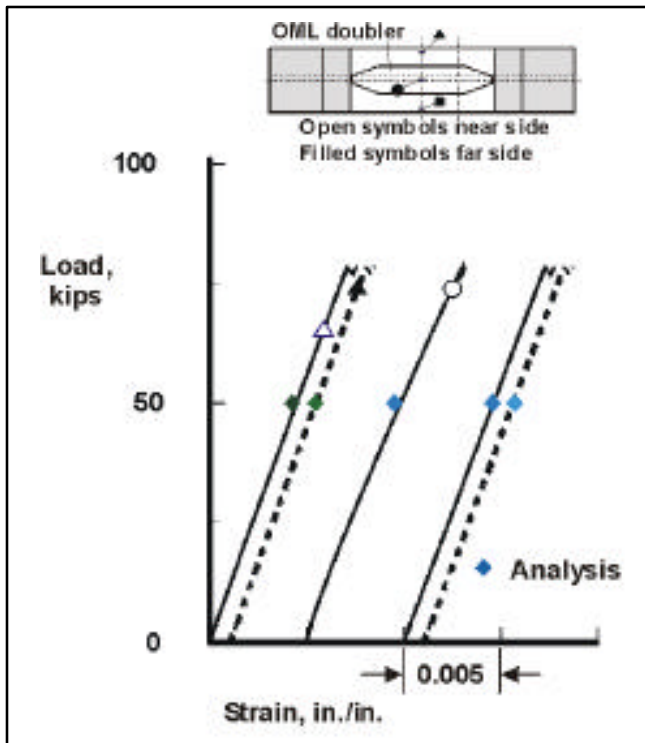

a) Results at mid-length

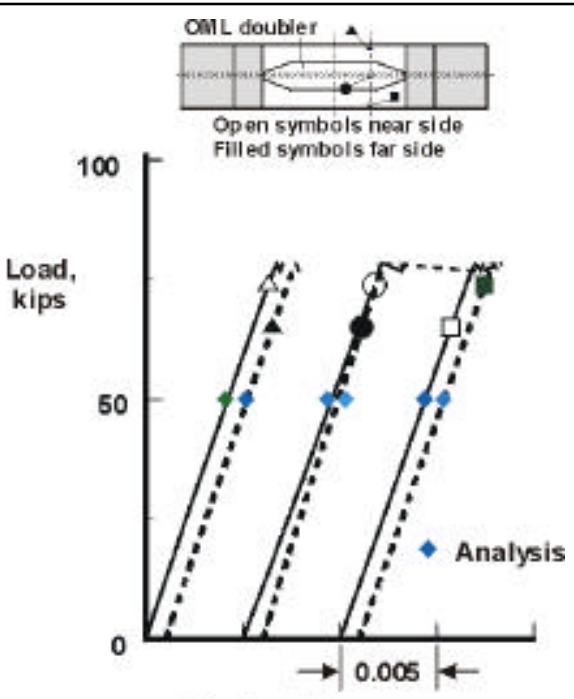

Strain, in./in.

b) Results at quarter point

Figure 15. Load as a function of strain for the no-IML specimen. 


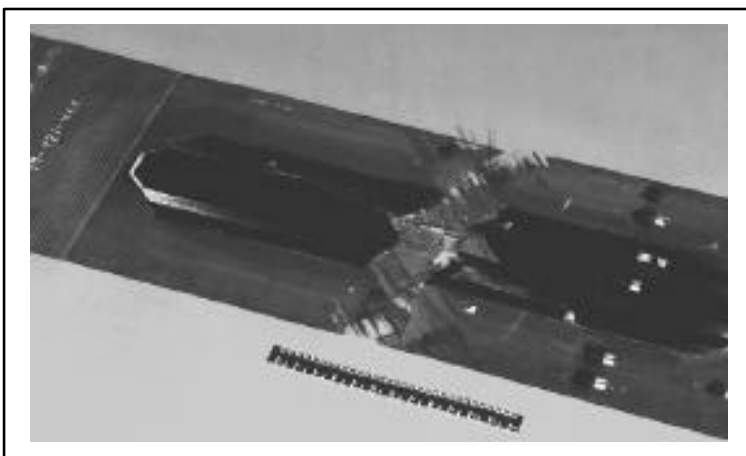

Figure 16. Failed no-IML specimen.

slope of the experimental curve between 50 kips and 75 kips is $181.9 \mathrm{kips} / \mathrm{in}$. Also shown in the figure is the computed elongation, which has a slope of the 237 kips/in. The stiffness of the no-IML specimen is 77 percent of the computed stiffness.

The computed strains are shown in figure 15 as the diamond symbols. Good agreement is shown between the computed and experimental strains in the skin (triangles and squares) and are within 10 percent of the experimental strains.

Comparison of Concepts When comparing the results of the repaired specimens to the baseline specimen, consideration should be given to the unusually high failure strain and failure strength of the baseline specimen. As noted earlier the failure strain in the baseline specimen is more than three times the typical operating design ultimate strain for tape material and more than two times the target design strain for the repaired specimens. A better

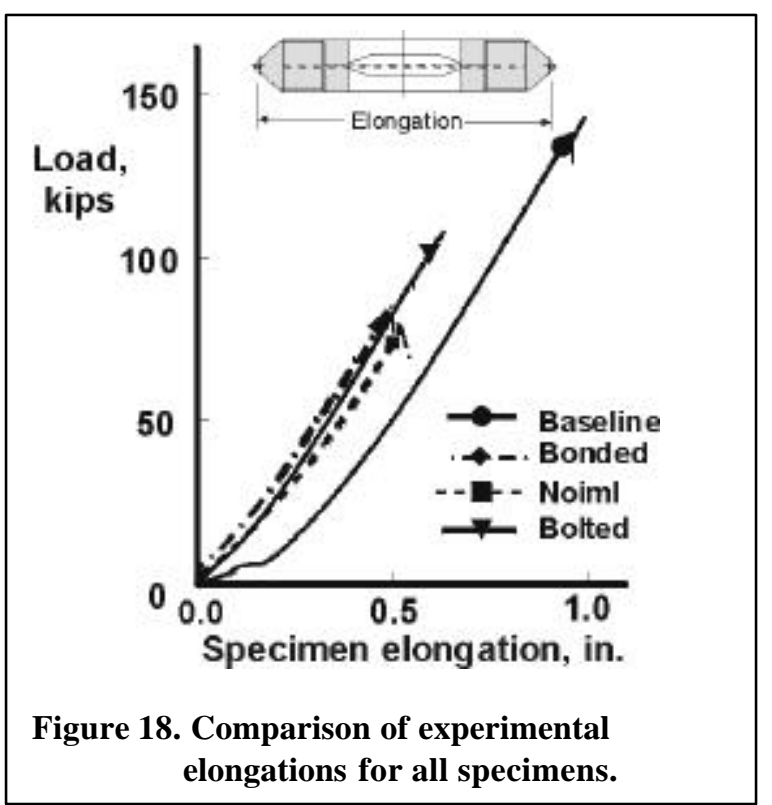

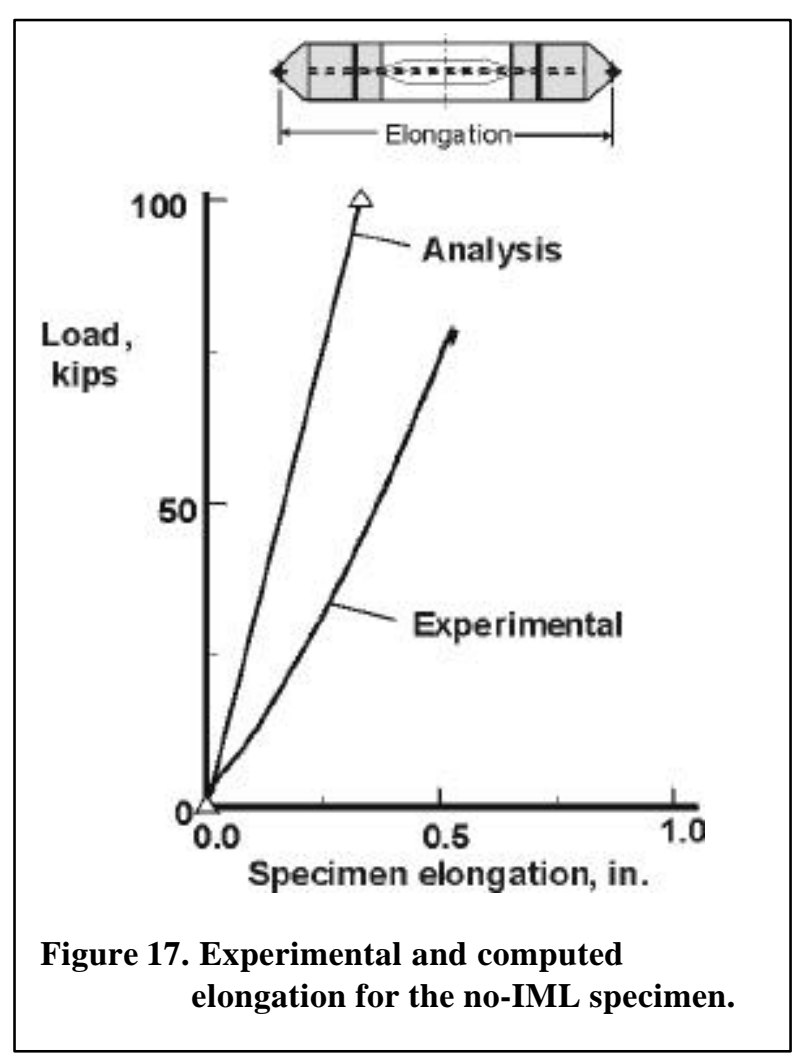

approach would be to compare the strain at failure in the repair with the far-field strain (Column 5 and 6 in Table 1). The strain in the repair is 63 percent of the far-field strain for the bonded and bolted repairs and 87 percent for the no-IML repair. Comparing the repair concepts to the target design strain indicates that the bolted specimen and the no-IML specimen exceed the target strain and the strain at failure of the bonded specimen is 84 percent of the target strain. As shown in the previous sections the strength retention of the repaired specimens varied from 55 percent to 76 percent when compared to the baseline specimen strength. Again consideration should be given to high baseline strength when using the strength retention as design consideration for the repair concept.

A comparison of the elongation of each repair concept as a function of the applied load is shown in figure 18 . Since the slopes of the curves shown in figure 18 are very similar, these results suggest that the repair had little effect on the specimen axial stiffness and these repair techniques could be used in a stiffness critical application with minimal impact.

\section{$\underline{\text { Summary }}$}

Repair concepts for carbon-epoxy rod reinforced laminates that have fully severed rods has been developed. The three different concepts that have been evaluated are: (a) bonded repair with outside moldline 9 
and inside moldline doublers; (b) bonded repair with fasteners; and (c) bonded repair with an outside moldline doubler only. One specimen of each repair concept has been fabricated and tested. The bonded repair with fasteners and the bonded repair with an outside moldline doubler exceeded a target design strain set for the repair concepts. The strain in the repair at failure was 63 or 87 percent of the far-field strain. The strength retention of the repair concepts varied from 55 percent to 76 percent when compared to an unrealistically high baseline strength.

The stiffness of the repairs are compariable to one another and their use would have minimal effect on a stiffness designed structure. The predicted strains from the finite element analysis compared well with the experimental strains.

\section{$\underline{\text { References }}$}

1. Nunn, K. E. and Dompka, R. V., DMLCC-BW PHASE I Interim Report for Period October 1991 - October 1992, WL-TR-92-8009, November 1992.

2. Nunn, K. E. and Dompka, R. V., DMLCC-BW Phase II Interim Report for Period October 1992 - October 1993, WL-TR-94-8007, November 1994.

3 Baker, D. J., Nunn, K. E., Rogers, C. W., Dompka, R. V., and Holzwarth, R. C., Design, Development and Test of a Low-Cost, PultrudedRod-Stiffened Wing Concept and its application to a Civil Tiltrotor Transport, presented at the $10^{\text {th }}$ DOD/NASA/FAA Conference on Fibrous Composites in Structural Design, November 1993, proceedings NAWCADWAR-94096-60, April 1994.

4. Rousseau, C. Q., Baker, D. J., and Chan, W. S., Analysis and Testing of a Rod-Reinforced HatSection Stringer, presented at the $36^{\text {th }}$ Structures, Structural Dynamics and Materials Conference
New Orleans, LA, April 10-12, 1995. AIAA Paper 95-1509.

5 Baker, D. J. and Rousseau, C. Q., Design and Evaluation of a Bolted Joint for a Discrete CarbonEpoxy Rod-Reinforced Hat Section, presented at the $11^{\text {th }}$ DOD/NASA/FAA Conference on Fibrous Composites in Structural Design, Ft. Worth, TX, August 1996, Proceedings WL-TR-97-3008, April 1997.

6. Rousseau, C. Q. and Baker, D. J., Layer Termination in Rod-Reinforced Structures, presented at the American Helicopter Society National Technical Specialists Meeting on Rotorcraft Structures, Williamsburg, VA, October 30 - November 2, 1995

7. Baker, D. J. and Rogers, C., Analysis and Tests of Reinforced Carbon-Epoxy/Foam-Core Sandwich Panels With Cutouts, presented at the American Helicopter Society $52^{\text {nd }}$ Annual Forum, Washington, D.C. June 4-6, 1996 and published in the Journal of American Helicopter Society, Vol. 43, No. 2, April 1998, pp 120-132

8. Anderson, T. C., Holtzwarth, R. C., Design and Manufacture of Low-Cost Composite-Bonded Wing, presented at the $39^{\text {th }}$ Structures, Structural Dynamics and Materials Conference, Long Beach, Ca, April 2023, 1998, AIAA Paper 98-1870.

9. Cronkhite, J. D., Dompka, R., Anderson, T., Cost and Performance of a Bonded IML-Tooled Tiltrotor Wing, presented at the American Helicopter Society National Specialists Meeting on Affordable Composite Structures, Bridgeport, CT, October 7 - 8, 1998.

10. Baker, D. J., Rousseau, C. Q., Evaluation of CarbonRod Reinforced Crippling Strength Specimens, presented at the $40^{\text {th }}$ Structures, Structural Dynamics and Materials Conference, St. Louis, MO, April 1215, 1999, AIAA Paper 99-1282.

11. MSC/NASTRAN Users manual, Version 70.5, 1997. 